
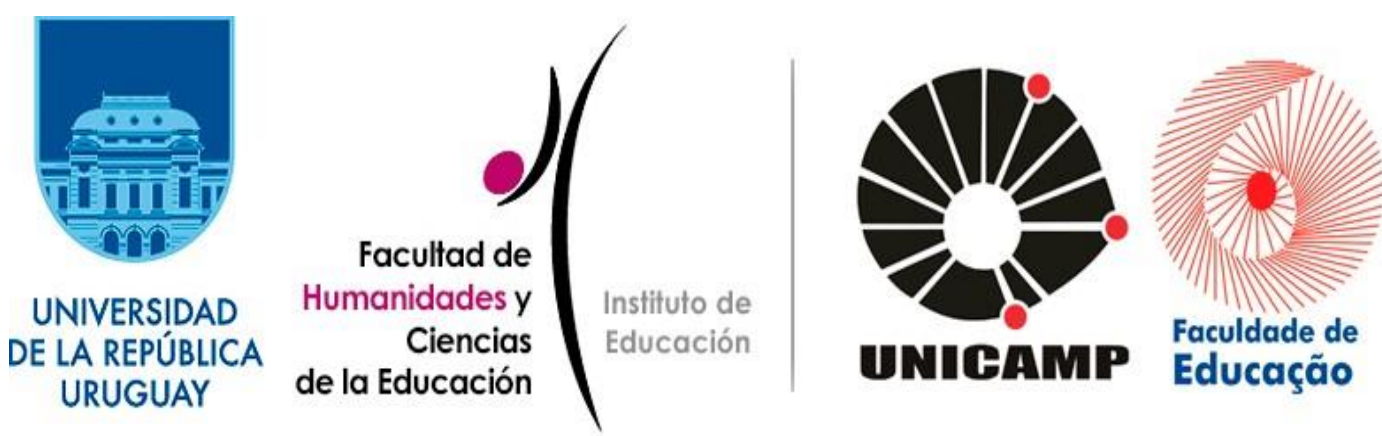

ARTÍCULO | ARTIGO

Fermentario V. 12, $\mathrm{N}^{\circ} 2$ (2018)

ISSN 16886151

Instituto de Educación, Facultad de Humanidades y Ciencias de la Educación,

Universidad de la República. www.fhuce.edu.uy

Faculdade de Educação, UNICAMP. www.fe.unicamp.br

Santiago Maldonado metido a educador: Aportes para pensar

las relaciones entre laicidad y pensamiento crítico a partir de la polémica en liceo de San Carlos

Santiago Maldonado became an educator: Contributions to

think about the relationships between secularism and critical

thinking from the controversy in the San Carlos high school

Cecilia Sánchez ${ }^{1}$

DOI: https://doi.org/10.47965/fermen.12.2.5

\title{
Resumen
}

A partir del rescate de la polémica generada en un Liceo de San Carlos por la colocación de un cartel que enuncia: “Los estudiantes del liceo $N^{\circ} 1$ nos preguntamos ¿Dónde está Santiago Maldonado?”, este trabajo intenta sostener que uno de los sentidos del término laicidad emergentes en la valoración del hecho, es su asimilación con la neutralidad. A esta interpretación de la laicidad se contrapone otra,

\footnotetext{
${ }^{1}$ Docente de Filosofía, estudiante avanzada de la Licenciatura en Educación (FHCE) y maestranda en Ciencias Humanas, opción Estudios Latinoamericanos (FHCE). Email: elmaildececilia@gmail.com
} 
que se entiende es más propicia al desarrollo de la autonomía y el pensar crítico, objetivos de la educación para una sociedad que se proyecta democrática y plural.

Palabras clave: laicidad, conducta laica, actitud crítica.

\begin{abstract}
A partir do resgate da polémica gerada em uma escola do ensino médio de San Carlos pela colocação de um cartaz que afirma: “Os estudantes do liceo $N^{\circ} 1$ perguntamos: a onde está Santiago
\end{abstract} Maldonado?", este artigo tenta argumentar que um dos sentidos do termo laicidade emergente na valorização do acontecimento é sua assimilação com a neutralidade. Confrontámos outra interpretação da laicidade que acreditamos tende ao desenvolvimento da autonomia e do pensamento crítico, objetivos educacionais para uma sociedade que se projeta democrática e plural.

Keywords: laicidade, conduta laica, atitude crítica.

\author{
¿Por qué no digo lo que pienso? \\ ¿Me llevarán? ¿Me van a llevar si te lo digo? \\ ¿Por qué, por qué, por qué, por qué, por qué, por qué? \\ ¿Por qué pienso lo que digo? \\ ¿Me llevarás? ¿Me vas a llevar si no lopienso?
}

Daniel Viglietti

\title{
Introducción
}

A inicios de la década del '70 Reina Reyes advertía la necesidad de diferenciar el contenido ideológico del término laicidad de los distintos sentidos que ha ido incorporando el concepto en su uso. Se trata de un término polisémico, siempre presente en el debate educativo uruguayo y con la particularidad de ser característico de nuestro país, es decir, que da cuenta de procesos histórico-políticos propios del Uruguay. Debatir en torno a la laicidad implica instalarnos en un terreno de diversidad de posiciones y de prácticas educativas y políticas. Por esto, no es posible, ni deseable, construir una definición única y totalizadora, que englobe los distintos aportes teóricos que existen y la diversidad de sentidos a la que hacíamos referencia. 
En este trabajo pretendemos analizar algunos sentidos de la laicidad que entendemos salen a escena a partir de la noticia del pedido de retiro por parte de la Dirección del Liceo $N^{\circ} 1$ de San Carlos (Maldonado) de un cartel colocado por el Centro de Estudiantes de dicha Institución preguntando por el paradero del joven argentino Santiago Maldonado. Nos proponemos mostrar, además, que algunas formas de entender la laicidad no propician e incluso obstaculizan el desarrollo de la autonomía y del pensamiento crítico de los estudiantes.

Es importante aclarar que tomamos este acontecimiento como punto de partida y que excede las intenciones del trabajo, realizar un análisis detallado del mismo, lo cual implicaría indagar, en primer lugar, los hechos de primera mano y abarcar las múltiples posturas que posiblemente surgieron frente a lo ocurrido.

\title{
Breves reflexiones sobre la polémica en el Liceo de San Carlos
}

El día 10 de octubre de este año El Observador titula: "Cartel sobre Santiago Maldonado en liceo de San Carlos generó polémica. El alcance del principio de la laicidad en la educación llevó a que la dirección se opusiera a la iniciativa de los estudiantes”. A continuación extraemos textualmente algunos breves fragmentos de dicha noticia:

\begin{abstract}
El subdirector del centro educativo, Fenando Mazzoni, dijo a El Observador que esa iniciativa no fue bien recibida al entenderse que podía estar en tensión con lo que establece la ley general de Educación de 2008 en su artículo 17. Allí se define el principio de laicidad que debe regir en la educación y debe asegurar, entre otras garantías, "la pluralidad de opiniones y la confrontación racional y democrática de saberes y creencias".

En tanto, los estudiantes basaron su defensa en el principio de la libertad de expresión, según ellos, avalado en el Estatuto del Estudiante. Ese documento consigna la referida libertad pero añade, en el artículo 5, que "deberá ejercerse de acuerdo con las previsiones constitucionales, legales y las del presente Estatuto".

"Están los desaparecidos en nuestra dictadura acá en Uruguay, los desaparecidos en plena democracia, la trata de blancas y otros problemas más, y estos chicos, sin embargo, deciden expresarse solamente sobre este asunto", señaló Mazzoni, al ser consultado sobre qué apreciación hizo la dirección cuando "de ninguna manera" permitió que la pancarta permaneciera más que unas horas ${ }^{2}$.
\end{abstract}

Como decíamos en la introducción, la multiplicidad de sentidos y usos del término laicidad torna complejas las discusiones sobre dicho asunto. Además, el contenido de la noticia está atravesado por múltiples valoraciones del periodista y por las orientaciones políticas de El Observador, cuyo análisis

\footnotetext{
${ }^{2}$ Extraído de: https://www.elobservador.com.uy/cartel-santiago-maldonado-liceo-san-carlos-genero- polemica-n1129364
} 
excede las pretensiones de este trabajo. Sin embargo, partiendo de lo que en la noticia se enuncia entendemos que, en primer lugar, tomar el Artículo 17 de la Ley de Educación como justificación del pedido de retiro del cartel es, al menos, forzar dicho artículo. En el mismo se expresa:

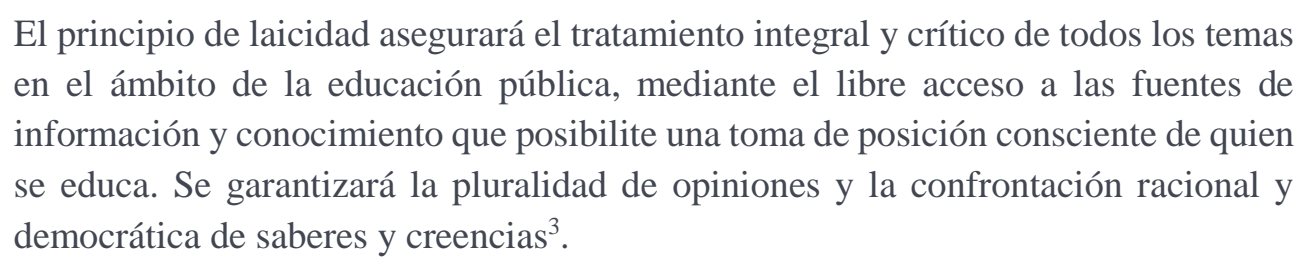

Se explicita en sus líneas el tratamiento de forma integral y crítica todos los temas en el ámbito de la educación pública, garantizando el acceso a la información para la toma de postura de los estudiantes, desde una perspectiva plural y democrática. Es legítimo pensar que, justamente en nombre del principio de laicidad, se pueda discutir y problematizar el caso del joven desaparecido. Podemos decir incluso que es más bien contrario al espíritu de dicho artículo la censura de ciertos temas y de algunas posturas.

Se podría afirmar que lo que se discute no es la postura en sí misma, sino el grado de conocimiento del tema y de reflexión previa por parte de los estudiantes que instalaron la pregunta por Santiago Maldonado en el liceo. Quizás a eso hacía referencia el subdirector de la Institución al llamar la atención frente al hecho de que "Están los desaparecidos en nuestra dictadura acá en Uruguay, los desaparecidos en plena democracia, la trata de blancas y otros problemas más, y estos chicos, sin embargo, deciden expresarse solamente sobre este asunto". Si tal es la interrogante, podríamos pensar que la situación es propicia para discutir en torno al tema, ampliando las fuentes de información para enriquecer el pensamiento y el debate, pero su censura es discutible. Incluso, el caso del joven desaparecido puede ser pensado como puntapié para trabajar temáticas contemporáneas y sumamente relevantes que él mismo pudo relacionar con la situación del joven argentino.

En este sentido retomamos las palabras de Manuel Becerra (2017), docente argentino quien a propósito de la polémica por introducir al aula el caso de Santiago Maldonado, escribió un artículo en Revista Anfibia que consideramos viene a colación. Es importante destacar que en Argentina muchos docentes enfrentaron la persecución, acusaciones de "adoctrinamiento" y cuestionamientos múltiples por hacer referencias al caso. Incluso, el gobierno instaló una línea telefónica para que la ciudadanía denuncie a los educadores que lo hagan. Becerra llama la atención sobre el hecho de que, son

\footnotetext{
${ }^{3}$ Extraído de: http://www.ces.edu.uy/ces/index.php?option=com_content\&view=article\&id=569\%3Aley- no-18437-leygeneral-de-educacion-160109\&Itemid=78
} 
justamente sus estudiantes los que traen el tema al aula, por la repercusión mediática que tuvo la temática.

La desaparición de Santiago Maldonado, y su rebote social y mediático, permiten trabajar desde ese caso cuestiones relacionadas a los Derechos Humanos, la propiedad de la tierra, los latifundios, los derechos de los pueblos originarios, el concepto de desaparición forzada, la vigencia de la ley, las relaciones de fuerzas entre el Estado y los empresarios, entre una infinidad de etcéteras que figuran no en una sino en varias materias de cualquier Diseño Curricular - esto es, la definición concreta de contenidos- de las escuelas argentinas. Por su parte, los marcos pedagógicos de toda la normativa educativa vigente impulsan la formación de sujetos críticos, solidarios, comprometidos con el sistema democrático, con herramientas para analizar su comunidad, su país y su mundo.

Dicho de otro modo: no somos docentes subversivos - por usar una categoría que parece haber recobrado vigencia- quienes metemos a Maldonado con fórceps en el aula, sino el mismo Estado el que nos pide que busquemos las formas de trabajar esos contenidos. Y este caso logró la materia prima, la piedra filosofal del acto educativo: alumnas y alumnos preguntando: ¿Dónde está Santiago Maldonado? (Becerra, 2017)

Siguiendo a Reina Reyes (1992), podemos decir que justamente una educación laica es la que evita este tipo de dogmatismos y falsas neutralidades, reconociendo en el otro un sujeto libre e igual. Desde esta óptica, la apelación a la autoridad no parece ser compatible con la educación laica.

La educación laica evita posiciones dogmáticas, conduce al niño a la observación objetiva de la realidad, cultiva la reflexión, da oportunidades para la espontaneidad, crea conciencia de valores comunes y hace posible una posterior elección personal de aquellos valores que son susceptibles de diversidad. La educación laica respeta las características intelectuales y afectivas de cada niño y tiende a lograr una integración del pensamiento reflexivo con el sentimiento de igualdad de los hombres, aspectos inseparables de la conducta laica. (Reyes, 1972, p. 81-82)

La defensa de los estudiantes, según expresa la prensa ya citada, se basa en el Artículo 5 del Estatuto del Estudiante, que hace referencia a la libertad de expresión:

El joven tendrá derecho a la libertad de expresión del pensamiento, a cuyos efectos se incluye la de buscar, recibir y difundir informaciones e ideas. Su opinión se tendrá debidamente tenida en cuenta, en función de su edad y madurez, respetándose en todo caso sus creencias e ideas religiosas o de otra índole. Este derecho deberá ejercerse de acuerdo con las previsiones constitucionales, legales y las del presente Estatuto 4 .

Corre por cuenta de El Observador que lo único que se destace del Artículo sea el fragmento final y no la consagración de la libertad de pensamiento en sí misma. Parecería que la libertad de expresión

\footnotetext{
${ }^{4}$ Extraído de: https://www.ces.edu.uy/ces/images/stories/2014/abril2014/Estatutos/estatuto\%20estudiante.pdf
} 
encuentra un límite en la laicidad, cuando por el contrario y siguiendo a Reina Reyes, podemos decir que la libertad de pensamiento y la libertad de expresión son justamente condiciones esenciales del principio de laicidad. La consagración de estas libertades ha de ser el fin más elevado de una sociedad democrática. "Ese juego de libertades y de respeto a esas libertades, esa relación de derecho y de deber, es lo que, en esencia constituye la LAICIDAD." (Reyes, 1972, p.70) La libertad de expresión reclama relaciones de igualdad entre los sujetos, para el respeto de la libertad de pensamiento y expresión de los otros, pero también supone condiciones para el ejercicio del pensar. La libertad de expresar libremente lo que se piensa solo es plana cuando lo que pensamos también fue elaborado libremente. "El derecho a expresar nuestros pensamientos tiene algún significado tan solo si somos capaces de tener pensamientos propios" (Fromm en Reyes, 1972, p. 69).

La laicidad, como principio abstracto, se concreta en lo que Reyes llama conducta laica, que implica "una actitud intelectual y moral por la cual la persona realiza su autonomía en relaciones recíprocas con otras conciencias" (Reyes, 1972, p. 71). La exigencia del derecho de pensar y expresarse libremente debe exigirse universalmente, reconociendo ese derecho a los otros. La conducta laica se evidencia en el encuentro con los otros y, en particular, en el encuentro con quienes piensan diferente.

\section{Crítica y autonomía}

Si la laicidad en una sociedad democrática implica la posibilidad de reflexionar sobre todos los temas desde una perspectiva informada, respetuosa de la diferencia, y esta se concreta en el encuentro con el otro en el debate argumentativo e intelectualmente honesto, ella no puede ser disociada del fomento de la crítica y la autonomía de los sujetos.

En ¿Qué es la Ilustración? Kant define la ilustración como "la liberación del hombre de su culpable incapacidad”. Esta incapacidad implica no poder pensar por uno mismo, no poder ejercer el pensamiento autónomo, sino tutelado. El hombre es culpable de esta incapacidad en la medida en que, teniendo la posibilidad de ejercer su pensar sin la tutela de otro, no posee el valor para hacerlo. “¡Sapere aude! ¡Ten el valor de servirte de tu propia razón!: he aquí el lema de la ilustración” (Kant, 2004, p. 33). La emancipación exige coraje, es un acto de valentía, requiere abandonar las comodidades de una vida tutelada. La búsqueda de fundamentos y de sentidos, el pensar auténtico, exige estudio, rigor conceptual, esfuerzo. En este sentido, Kant parece realizar una crítica a la burguesía y su forma de vida: "Con sólo poder pagar, no tengo necesidad de pensar” (Kant, 2004, p. 33). La modernidad, a pesar del predominio de la razón, no ha desarrollado todas las potencialidades humanas en cuanto al pensamiento, el progreso de la técnica ha fomentado la comodidad. El 
desarrollo tecnológico no ha liberado sino que oprime al hombre. Sin pretender forzar a Kant podemos encontrar en esta idea un germen de la crítica a la razón instrumental.

Es, pues, difícil para cada hombre en particular lograr salir de esa incapacidad,
convertida casi en segunda naturaleza. (...) Principios y fórmulas, instrumentos
mecánicos de un uso, o más bien abuso, racional de sus dotes naturales, hacen a veces
de ligaduras que le sujetan a ese estado. Quien se desprendiera de ellas apenas si se
atrevería a dar un salto inseguro para salvar una pequeña zanja, pues no está
acostumbrado a los movimientos desembarazados. (Kant, 2004: p. 33-34)

Desde una perspectiva contemporánea, Mumford (1992) realiza un recorrido por el desarrollo de la técnica y profundiza esta observación kantiana. A su entender, el desarrollo de la técnica y la tecnología, que originariamente consideraron la vida y las necesidades humanas, se han desligado de esta intención primera en el devenir histórico, olvidando la naturaleza y postergando el desarrollo pleno de la humanidad.

El desarrollo del pensamiento científico se vio fomentado en gran medida por el advenimiento del capitalismo y la sustitución de una economía de trueque (basada en reservas y monedas concretas) por una economía de dinero (con referencia permanente a símbolos abstractos de la riqueza) que instalan la abstracción y el cálculo en la vida cotidiana de los hombres de la cuidad. La "economía de subsistencia" se tornó “economía de adquisición”, sustituyendo los "valores vitales” por los "valores dinerarios" y construyendo preocupaciones cada vez más abstractas.

Este último hecho era especialmente importante en lo que se refiere a la vida y al pensamiento: la busca del poder por medio de abstracciones. Una abstracción reforzaba la otra. El tiempo era dinero: el dinero era poder: el poder exigía el fomento del comercio y de la producción." (Mumford, 1992, p. 21)

El desarrollo de la técnica moderna es deudor de la gestación de la abstracción del pensamiento a la que hacíamos referencia, de nuevos intereses pragmáticos y fundamentalmente de las demandas directas del capital para la producción fabril y la industria de la guerra. El capitalismo se apropia de la máquina ${ }^{5}$ para fomentar la ganancia particular y no el bienestar social. Esto explica, según Mumford, que la industria artesanal haya sido sustituida por los productos de la máquina, aunque muchas veces esa producción fuera de calidad inferior a la del artesano. El beneficio estaba en la creación de un producto que pueda sustituir al anterior y sea menos dependiente de variaciones o irregularidades en la producción. (Mumford, 1992, p. 38) Ese afán de creación se tornaría posteriormente un deber,

\footnotetext{
${ }^{5}$ El autor establece una distinción entre la palabra máquina, para referirse a objetos específicos y el término "la máquina" como referencia abreviada a todo el complejo tecnológico, que abarca el conocimiento, las pericias y las artes derivadas de la industria o implicadas en la nueva técnica. Este complejo tecnológico incluye varias formas de herramientas, instrumentos, aparatos y obras, así como máquinas propiamente dichas. (Mumford, 1992, p. 15)
} 
despojando el desarrollo de la técnica de todo juicio crítico: los inventos se tornaron buenos en sí mismos, fueran acompañados o no de un beneficio para las personas. "Si la sanción de la utilidad hubiera sido predominante, la invención habría adelantado más rápidamente en aquellos sectores donde la necesidad humana era más aguda, en la alimentación, en la vivienda, en la vestimenta (...)” (Mumford, 1992, p. 43)

La máquina, despojada de ideología, fue conquistando cada vez más terreno en la vida humana. Las funciones del cuerpo humano son también imitables y, por tanto, sustituibles. El ser humano podrá ser concebido como engranaje de la máquina, e incluso ésta cobrar existencia independiente del ser humano.

En Crítica y Aufklärung (1995), Foucault establece un sentido del término crítica como des-sujeción y advierte la raíz kantiana de dicha noción. Si la gubernamentalización implica el despliegue de un movimiento de sujeción de individuos por medio de mecanismos de poder que se pretenden verdaderos y absolutos, la crítica es la posibilidad del sujeto de visibilizar esos mecanismos, de desnaturalizar sus sedimentos y verdades totalizadas; un ejercicio de resistencia, de lucha contra lo dado $^{6}$. Desprenderse de esas ataduras es des-sujetarse e implica plantear las condiciones de posibilidad del pensar, lo cual también propone Foucault al señalar que la crítica debe desentrañar el haz de relaciones que ata el poder, la verdad y el sujeto.

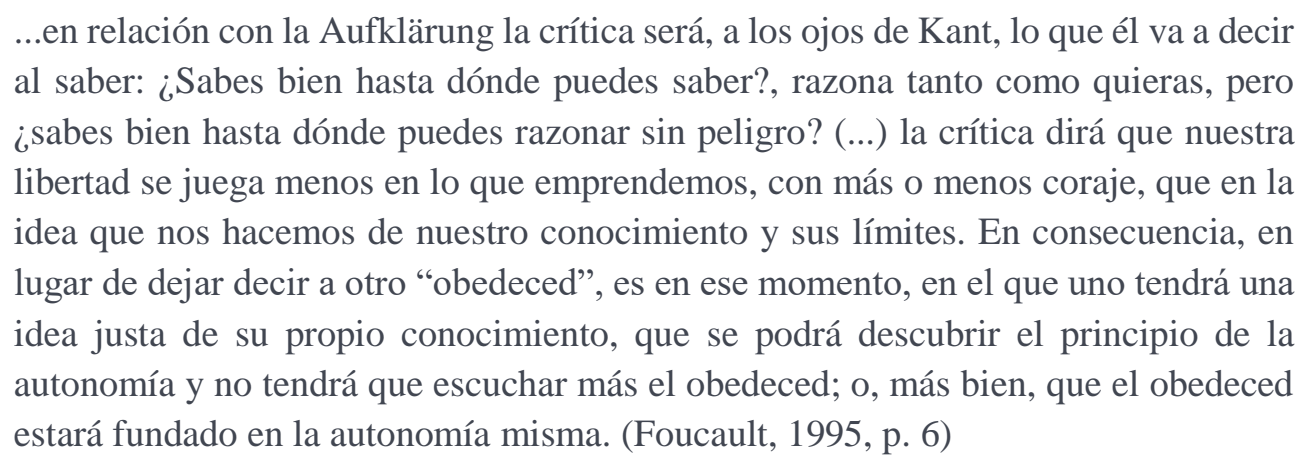

Podemos decir que la actitud crítica implica el establecimiento de criterios para buscar fundamentos, condiciones de posibilidad de nuestros juicios sobre la realidad. El pensar crítico debe ser capaz de demostrar qué criterio usa y fundamentar porqué es relevante ese criterio. Quien piensa por sí mismo

\footnotetext{
${ }^{6}$ En términos del filósofo "el núcleo de la crítica es, esencialmente, el haz de relaciones que ata el poder, la verdad y el sujeto, uno a otro, o cada uno a los otros dos. Y si la gubernamentalización es ese movimiento por el cual se trataba, en la realidad misma, de una práctica social de sujeción de individuos por medio de mecanismos de poder que reclaman para sí una verdad; pues bien, diría que la crítica es el movimiento por medio del cual el sujeto se arroga el derecho de interrogar a la verdad sobre sus efectos de poder y al poder sobre sus discursos de verdad. En otras palabras, la crítica será el arte de la in-servidumbre voluntaria, el arte de la indocilidad reflexiva. La crítica tendría esencialmente por función la des-sujeción en el juego de la que pudiéramos llamar la 'política de la verdad'. (Foucault, 1995, p. 5)
} 
es capaz de generar sus propios juicios. Esta capacidad nos permitiría constituirnos como seres autónomos. El fundamento de la autoridad ya no estaría en una imposición exterior, sino en un pensar consciente y crítico. Si el pensar crítico nos lleva a aceptar la autoridad existente y a fundamentar su poder, no parecería haber problemas, la cuestión surge cuando nos conduce a su rechazo. La distinción kantiana de los usos público y privado de la razón supone el cuestionamiento sin dejar de obedecer. Pero, si en algún momento no se desobedece no cambiará lo que se cuestiona, será siempre una crítica declarativa, que no conduce a transformaciones.

Para Foucault la actividad crítica se dirige a las prácticas, valores, discursos, instituciones, y su objeto serían los contenidos de la filosofía, la ciencia, la política, la moral, etc. Ella no es disociable de la transformación, siendo medio o condición de posibilidad de un porvenir distinto, pero no constituye su ámbito el visualizar alternativas concretas o propuestas para fundar ese porvenir. Desnaturalizar lo dado, instaurar la sospecha de lo habitual y de lo obvio sería la competencia de la actividad crítica, desligándose de una actitud intelectual "vanguardista"7.

Suspender la obviedad es el primer paso en la crítica: se trata de interrogar la realidad, de tornarla más compleja; explicitar los supuestos en los que descansan nuestras prácticas y discursos, nuestros vínculos con los demás y con el mundo; cuestionar las ideas directrices, los valores y las creencias que subyacen a los saberes y a las prácticas sociales. En este sentido, podemos decir que la crítica es una herramienta esencial para expandir el pensamiento e interpretar la realidad. (Foucault, 1981)

Reina Reyes opone a la educación laica, lo que denomina educación dogmática la cual "cultiva hábitos mentales de aquiescencia, de sometimiento a la voluntad de otros y sentimientos de culpabilidad si se desobedece, hábitos y sentimientos opuestos a la determinación” (Reyes, 1972, p. 84). Una educación que procure ser laica debe fomentar el pensamiento crítico sobre la realidad y brindar al educando las condiciones que posibiliten poner a discusión las ideas heredadas de forma acrítica. En este sentido, la dimensión ética del acto educativo se torna sumamente relevante. Educar no puede tornarse imposición de verdades reveladas o adquiridas por el educador. Favorecer el ejercicio del pensamiento auténtico y reflexivo no puede confundirse en ninguna medida con enseñar qué pensar. En una relación asimétrica estos niveles pueden yuxtaponerse, sea de forma intencional o no.

\footnotetext{
${ }^{7}$ Así lo expresa el filósofo: "La crítica no existe sino en relación con algo distinto de ella misma. Ella es instrumento, medio para un porvenir que ella ni sabrá ni será. Es una mirada sobre un dominio en el que quiere jugar el papel de policía y en el que no es capaz de hacer la ley.” (Foucault, 1995, p. 5-6)
} 


\title{
El miedo a la pregunta: laicidad y neutralidad
}

Consideramos que existe una concepción sobre la laicidad heredada de la última dictadura militar que, de forma más o menos explícita, sostiene que la laicidad supone neutralidad frente a ciertas temáticas religiosas y políticas que plantean diversidad de opiniones. El caso de Santiago Maldonado entraría dentro de este grupo. Sin embargo, podemos decir que la educación toda se mueve en el terreno de la contingencia y la diversidad de criterios. Esa es justamente su riqueza.

\begin{abstract}
... la escuela [pública] no tiene legitimidad para tomar posición por una orientación frente a otras, para enseñar una visión única del amor y de la amistad, o sobre los modos de ser varón y de ser mujer. Ni la formación que reciben los maestros ni el marco normativo de la tarea habilitan esto. Sin embargo, esto no significa que la escuela deba permanecer silenciosa y evitar que estos temas aparezcan, sino que tiene la responsabilidad de ampliar el horizonte cultural dentro del cual los estudiantes construyen sus valoraciones, ofreciendo vías de contraste. (...) No se trata meramente de tolerar las diferencias, sino de valorar la diversidad como lo más rico de la experiencia humana, suscitando la comprensión del sentido de diferentes opciones éticas y culturales. (Siade, 2007, p. 112)
\end{abstract}

Siede postula el pluralismo como superación de la pretendida neutralidad escolar. Reconocer las diferencias, siempre en el marco de la lucha por la igualdad de derechos, dando lugar a la convivencia de múltiples valoraciones. Los jóvenes que llegan a las instituciones educativas reciben múltiples mensajes en relación a cómo vivir, en torno a lo bueno y lo justo, de su familia, de los medios de comunicación, de los educadores, de sus grupos de pares. En una sociedad democrática, no es posible, ni deseable, disputar por un único sentido válido.

La riqueza de la diversidad humana está en el amplio abanico de las configuraciones de sentido construidas por las comunidades en su experiencia histórica y con los sujetos en diálogo con ellas. Cualquier intento de diluir la diversidad, subsumirla en universales inmutables o combatirla desde políticas esencialistas de la identidad, no hace más que empobrecer el mundo en el cual vivimos, y esto ha ocurrido ya demasiadas veces. Una educación pluralista ha de abrirse a la multiplicidad de expresiones culturales en torno a valores, concepciones políticas y religiosas, estilos de vida y elecciones personales. (Siade, 2007, p. 111-112)

También Reina Reyes cuestiona la asimilación de la laicidad con la neutralidad y evidencia sus riesgos. No posicionarse frente a cuestiones de derechos humanos, en la búsqueda de igualdad y respeto por los derechos de todas las personas encubre, a su entender, una postura política cuestionable y un peligro para la democracia ${ }^{8}$. Una educación que pretenda aportar a la reflexión de

\footnotetext{
8 "La escuela laica contrariamente a lo que muchos creen o quieren hacer creer (...) no es neutra, no es respetuosa de todas las convicciones. (...) la escuela laica no puede respetar de ningún modo convicciones racistas, ni convicciones fascistas, ni diversas mentalidades retrógradas (por ejemplo, opuestas al progreso: contra los recursos de la medicina, contra el parto sin dolor, contra la educación sexual, etc., etc.) La laicidad no es neutra, es positiva, es una mentalidad de progreso. (...) El
} 
los estudiantes en torno a la sociedad en la que viven, aspire a la construcción de una ciudadanía comprometida y a la participación activa en la esfera pública, debería apartarse de falsas neutralidades y tender a generar espacios de apertura para la discusión argumentada y democrática sobre todos los temas, más aún cuando se trata de preocupaciones que emergen de los estudiantes, como es el caso de Santiago Maldonado que recuperamos inicialmente. La educación puede aportar al enriquecimiento de las opiniones, a desarrollar una argumentación sólida, libre de prejuicios y reflexionada. Instancias de este tipo no abundan para nuestros jóvenes y entendemos esencial potenciar.

\section{Comentarios finales}

La desaparición de Santiago Maldonado tomó gran relevancia mediática en Argentina, en nuestro país y a nivel internacional, la pregunta por su paradero y múltiples posturas en torno a lo sucedido invadieron los medios de comunicación, las redes sociales y las calles. La desaparición de este joven, en democracia, dio cuenta de un malestar social que en estos días se profundiza en el vecino país. La pregunta por Santiago trascendió los espacios de militancia e irrumpió en ámbitos académicos e intelectuales, el tema se instaló públicamente y fue puntapié de múltiples debates. Inevitablemente acabaría en los centros de estudio y en el aula.

En este trabajo intentamos sostener la idea de que la laicidad, a diferencia de la concepción que la emparenta con la neutralidad, es la intención de trabajar todos los temas de forma abierta, responsable y plural y que, en ese sentido, es condición esencial para el desarrollo del pensamiento crítico y la autonomía de nuestros estudiantes. Renunciar a esta dimensión implica un empobrecimiento de la tarea educativa y un recorte en el derecho a la educación.

Frente a los desafíos que plantea la laicidad, la preocupación no puede reducirse a pensar qué temáticas debieran ser vedadas en el aula, sino a evitar posturas dogmáticas, anti-reflexivas y autoritarias. El ideal democrático de la laicidad se encarna en la pluralidad y en la autonomía de los sujetos, en la medida en que desarrollen capacidad de juzgar la realidad tomando en cuenta las diversas perspectivas que estén a su disposición y formulando ideas originales.

\section{Bibliografía consultada}

Becerra, M. (2017) Profe, tengo una pregunta. En: Revista Anfibia. Recuperado de: http://www.revistaanfibia.com/cronica/profe-tengo-una-pregunta/ Última consulta: 23/12/17

silencio en aquellos dominios donde existe legítimamente pluralismo de opiniones, es un riesgo insidioso.” (Reyes, 1972, p. 98-99) 
Foucault, M. (1981) ¿Es importante pensar?, entrevista con D. Éribon. En: Libération. (15), París.

(1995) ¿Qué es la crítica? Crítica y Aufklärung. En: Daimon. (11) p. 5-25.

Kant, I. (2004) Filosofía de la historia. ¿Qué es la Ilustración? La Plata, Argentina: Ediciones Terramar.

Mumford, L. (1992) Técnica y civilización. Madrid: Alianza.

Reyes, R. (1972) El derecho a educar y el derecho a la educación. Montevideo: Editorial Alfa.

Siede, I. (2007) La educación política. Ensayos sobre ética y ciudadanía en la escuela. Buenos Aires: Paidós.

\section{Prensa citada}

El Observador (on line) Cartel sobre Santiago Maldonado en liceo de San Carlos generó polémica. (10/10/17) Extraído de: https://www.elobservador.com.uy/cartel-santiago- maldonado-liceo-san-carlos-genero-polemica-n1129364 Última consulta: 23/12/17

\section{Normativa consultada}

Estatuto del Estudiante: https://www.ces.edu.uy/ces/images/stories/2014/abril2014/Estatutos/estatuto\%20estudiant e.pdf

Ley General de Educación: http://www.ces.edu.uy/ces/index.php?option=com_content\&view=article\&id=569\%3Ale yno-18437-ley-general-de-educacion-160109\&Itemid=78 